\title{
Bypassing the Attitude-Behavior Gap: Using Social Identity and Norm Effects to Engender Sustainable Consumer Behaviors (An Abstract)
}

\author{
Guy Champniss, Hugh N. Wilson, Emma K. Macdonald, and Radu Dimitriu
}

\begin{abstract}
Most attempts to engender sustainable consumer behaviors rely on altruism appeals that are predicated on preexisting pro-social attitudes. This paper explores alternative means by which consumers can be encouraged to engage in socially and environmentally positive behavior. It is proposed that firms can use social influence effects among consumer groups assembled by the firm in the digital environment. Three controlled field experiments show that group influences among a temporary online consumer group can lead to collaborative behaviors, both between the consumer and the brand and between the consumer and other beneficiaries of the behavior. The paper finds support for the existence of two distinct group-level effects: a social identity effect within the newly formed group and an injunctive norm effect. These influence distinct behavioral outcomes, including commitment to purchase a sustainable product, the giving of time to the brand to help with its sustainability initiatives, and the giving of time to sustainability charities supported by the brand. Notably, these outcomes do not depend on the selection of individuals with supportive prior attitudes toward sustainability. The results extend knowledge on social consumer behavior, provide support for the argument that specific attitudes may not be necessary for specific behavioral outcomes, and present opportunities for practitioners to use social influence effects to elicit specific consumer behaviors, particularly in the online environment.
\end{abstract}

\footnotetext{
G. Champniss

Enervee Corporation, Venice, CA, USA; http://guy@enervee.com

H.N. Wilson $(\bowtie) \bullet$ E.K. Macdonald • R. Dimitriu

Cranfield School of Management, Cranfield, United Kingdom

e-mail: hugh.wilson@cranfield.ac.uk; emma.macdonald@cranfield.ac.uk;

radu.dimitriu@cranfield.ac.uk
} 